\title{
Polyelectrolyte Multilayers on Silica Surfaces: Effect of Ionic Strength and Sodium Salt Type
}

\author{
Jasmina Salopek, Anja Sadžak, Dino Kuzman, Josip Požar, Davor Kovačević*
}

\author{
Division of Physical Chemistry, Department of Chemistry, Faculty of Science, University of Zagreb, Horvatovac 102a, HR-10000 Zagreb, Croatia \\ * Corresponding author's e-mail address: davor.kovacevic@chem.pmf.hr
}

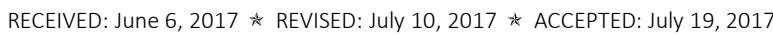

THIS PAPER IS DEDICATED TO PROF. MIRJANA METIKOŠ-HUKOVIĆ ON THE OCCASION OF HER BIRTHDAY

\begin{abstract}
The formation of polyelectrolyte multilayers on silica surfaces was investigated in the presence of binary 1:1 sodium salts ( $\mathrm{NaCl}, \mathrm{NaBr}$ and $\mathrm{NaNO}_{3}$ ) at various salt concentrations. The build-up of multilayers was monitored using electrophoretic light scattering and quartz crystal microbalance with dissipation monitoring techniques. As cationic polyelectrolyte poly(diallyldimethylammonium chloride) was used and as anionic poly(sodium 4-styrene sulfonate). The counterion specific formation of multilayers was observed at higher electrolyte concentrations and the more pronounced influence was observed in the case of nitrate and bromide than in the case of chloride salt. These results confirm that solely by adjusting the appropriate ionic strength and by choosing the electrolyte type, polyelectrolyte multilayers with various properties and structure can be obtained.
\end{abstract}

Keywords: polyelectrolyte multilayers, poly(diallyldimethylammonium chloride), poly(sodium 4-styrene sulfonate), silica, sodium salts, ionic strength, zeta-potential, QCM-D.

\section{INTRODUCTION}

$\mathbf{P}$ POLYELECTROLYTE MULTILAYERS (PEMs) are surface coatings obtained by alternate deposition of positively and negatively charged polyelectrolytes (polycations and polyanions) on a solid surface. Since 1991, when the layerby-layer method for formation of polyelectrolyte multilayers on various (mostly metal oxide) surfaces was introduced by Decher, ${ }^{[1]}$ the interest in the process of formation of such layered structures has been continuously growing. The ease of formation of multilayers motivated scientists to extend the type of constituents incorporated into such nanocomposites by including proteins, ${ }^{[2]}$ dendrimers, ${ }^{[3]}$ or DNA. ${ }^{[4]}$ Various experimental methods ${ }^{[5,6]}$ are being used enabling the better insight into the process of layer-bylayer deposition of polyelectrolytes for the preparation of PEMs. Very interesting results were obtained for example by ellipsometry, ${ }^{[7]}$ stagnation point optical reflectometry, ${ }^{[8-}$ ${ }^{10]}$ quartz crystal microbalance, ${ }^{[11]}$ optical waveguide lightmode spectroscopy ${ }^{[12]}$ and vibrational sum frequency generation spectroscopy. ${ }^{[13]}$
The applicational aspects of polyelectrolyte multilayers should be also stressed here. For example, the adsorption of biological or biomimetic samples onto certain synthetic material (in this case polyelectrolyte multilayers) could enable additional progress in the field of biosensing surfaces, tissue engineering and drug delivery. Polyelectrolyte multilayers are promising coatings onto which biological molecules (e.g. proteins) could be adsorbed. In the literature, ${ }^{[14-16]}$ several studies of protein adsorption on previously formed polyelectrolyte multilayers could be found. Müller and coworkers ${ }^{[14]}$ examined the sorption of HSA on poly(ethyleneimine)/poly(acrylic acid) multilayers using ATR FTIR spectroscopy, while Gergelly et al.[15] analysed adsorption of the same protein on poly(L-lysine)/ poly(glutamic acid) multilayer by Optical Waveguide LightMode Spectroscopy (OWLS) and AFM. The secondary structure of lysozyme and bovine serum albumin (BSA) adsorbed onto PAH/PSS multilayers was investigated by Schaaf and co-workers. ${ }^{[16]}$ They showed that the secondary structure of the proteins was somewhat altered upon adsorption onto the polyelectrolyte multilayers and that 
the structural changes were larger when the charges of the multilayer outermost layer and the protein were opposing. A special and very promising case is the possible application of polyelectrolyte multilayers as antibacterial coatings. Zan and Shu ${ }^{[17]}$ proposed a scheme of the procedure for fabricating polyelectrolyte multilayers containing silver ions or silver nanoparticles, which could be, used as effective antibacterial coatings. On the other hand, Wong and coworkers showed that the protein adsorption is drastically lowered on microbicidal hydrophobic/hydrophilic polyelectrolyte multilayers. ${ }^{[18]}$ It was shown recently ${ }^{[19]}$ that that the extent of adhered bacteria mostly depends on the type of terminating polyelectrolyte layer, although surface roughness and hydrophobicity should be also taken into account.

It is known ${ }^{[10]}$ that the PEM build-up strongly depends on various experimental conditions such as ionic strength, type of supporting electrolyte, $\mathrm{pH}$, polyelectrolyte concentration and even of degree of ionization. ${ }^{[20]}$ The influence of different salts (phosphates, chlorides and nitrates) and polyelectrolyte molecular weight on formation and erosion of multilayers on silica surfaces was investigated by means of optical reflectometry method. ${ }^{[8]}$ It was shown that at very low ionic strength (1 $\mathrm{mM}$ ) regular build-up of multilayers is observed independent of the salt used. However, at higher ionic strength dissolution also takes place, and the critical "glass transition ionic strength" needed for the multilayer to be dissolved depends on the salt used, as well as on the polycation/ polyanion pair studied. Tang and Besseling ${ }^{[10]}$ showed, using the same method, that, upon increasing ionic strength PEM growth patterns vary from linear for the lowest $\mathrm{NaCl}$ concentrations to exponential for higher $\mathrm{NaCl}$ concentrations.

Since layer-by-layer structures, like polyelectrolyte multilayers, play a very important role in surface modification processes and the effect of ionic strength and salt concentration on the process of PEM formation is not fully understood, we decided to study in more details the abovementioned effects on the formation of poly(diallyldimethylammonium chloride)/poly(sodium 4-styrenesulphonate) (PDADMAC/PSS) multilayers. In order to do so, we investigated the formation of PDADMAC/PSS multilayers in aqueous solutions of various electrolytes by means of zetapotential and quartz crystal microbalance with dissipation monitoring (QCM-D) measurements. For the low ionic strength regime we chose electrophoretic light scattering measurements for determination of particle velocity and, from this, the electrokinetic zeta-potential. The zeta-potential was calculated from mobility values using the Smoluchowski equation. Silica particles were used as the solid substrate. For higher ionic strength the experiments were performed by means of QCM-D. The experiments were performed in the presence of various sodium salts $\left(\mathrm{NaCl}, \mathrm{NaNO}_{3}\right.$ and $\mathrm{NaBr}$ ) in order to examine the effect of these salts on PEM formation process.

\section{EXPERIMENTAL}

\section{Materials}

Both polyelectrolytes, PDADMAC (poly(diallyldimethylammonium chloride) ( $\left.M_{\mathrm{w}} \leq 100000 \mathrm{~g} \mathrm{~mol}^{-1}, w=35.5 \%\right)$, and NaPSS sodium poly(4-styrenesulfonate) ( $M_{\mathrm{w}}=70000 \mathrm{~g}$ $\mathrm{mol}^{-1}$ ) were obtained from Sigma Aldrich and were used as received. The monomer functionalization degree $(f)$ of PDADMAC was determined by potentiometric titration with $\mathrm{AgNO}_{3}$ using chloride ion-selective electrode and the NaPSS functionalization degree was determined in DLS titration experiment with PDADMAC at low concentrations, assuming quantitative (1:1) reaction. The obtained values were $f=1$ for PDADMAC and $f=0.83$ for NaPSS. All the supporting electrolytes: sodium chloride, $\mathrm{NaCl}$, sodium nitrate, $\mathrm{NaNO}_{3}$ and sodium bromide, $\mathrm{NaBr}$, were also obtained from Sigma Aldrich and were of analytical purity grade. Silica powder, $\mathrm{SiO}_{2}$, for zeta-potential measurements $(d=$ $0.2-0.3 \mu \mathrm{m}$ ) was also obtained from Sigma Aldrich. All the solutions used for zeta-potential and QCM-D measurements were prepared by diluting the polyelectrolyte and salt stock solutions with deionized water.

\section{Methods \\ ZETA-POTENTIAL MEASUREMENTS}

Polyelectrolyte multilayers on silica particles were prepared as follows: In step 1, silica particles were suspended (mass concentration $=1 \mathrm{~g} \mathrm{dm}^{-3}$ ) in PDADMAC solution $\left(c_{\mathrm{m}}(\right.$ PDADMAC $\left.)=5 \times 10^{-3} \mathrm{~mol} \mathrm{dm}^{-3}\right)$ containing the appropriate amount of $\mathrm{NaCl}$ or $\mathrm{NaNO}_{3}$. The system was mixed for 10 min and centrifuged. After centrifugation particles were separated from the supernatant, rinsed with appropriate salt solution, and mixed again for 10 minutes. After rinsing and centrifugation, small amount of particles was resuspended in the solution of corresponding electrolyte by using ultrasound and, finally, mobility was measured. In step 2, the silica particles with the adsorbed PDADMAC layer were suspended in PSS solution $\left(c_{\mathrm{m}}(\mathrm{NaPSS})=5 \times 10^{-3} \mathrm{~mol} \mathrm{dm}^{-3}\right)$ containing again the appropriate amount of $\mathrm{NaCl}$ or $\mathrm{NaNO}_{3}$ to keep the ionic strength constant. The rest of the procedure in step 2 was the same as in step 1 . The same holds for the other added polyelectrolyte layers.

The electrophoretic mobilities of pure silica particles and of silica particles covered with polyelectrolytes were determined by means of a ZetaPlus instrument (Brookhaven Instruments Corporation) at $25{ }^{\circ} \mathrm{C}$ from the measured Doppler shift in angular frequency $(\Delta \omega)$ and the applied electric field $(E)$

$$
\Delta \omega=\left(\frac{2 \pi n}{\lambda}\right) E \mu \sin \theta
$$

where $n$ is the medium refractive index and $\lambda$ the incident wavelength. The scattering angle during measurement was 
constant $\left(\theta=15^{\circ}\right)$. The zeta-potential $(\zeta)$ was calculated from measured electrophoretic mobility by Smoluchowski equation

$$
\zeta=\frac{\mu \eta}{\varepsilon_{0} \varepsilon_{\mathrm{r}}}
$$

where $\varepsilon_{\mathrm{r}}$ is the relative permittivity, $\varepsilon_{0}$ the electric permittivity of vacuum, and $\eta$ is the viscosity.

\section{QCM-D MEASUREMENTS}

For QCM-D experiments, aqueous solutions of both polyelectrolytes were prepared at monomer concentration $c_{m}(\mathrm{NaPSS})=$ $c_{\mathrm{m}}(\mathrm{PDADMAC})=1 \times 10^{-3} \mathrm{~mol} \mathrm{dm}^{-3}$ and at salt $(\mathrm{NaCl}, \mathrm{NaBr}$ and $\mathrm{NaNO}_{3}$ ) concentrations, $c=0.1$ and $c=0.5 \mathrm{~mol} \mathrm{dm}^{-3}$.

Polyelectrolytes were alternately deposited on $5 \mathrm{MHz}$ quartz sensor with $50 \mathrm{~nm}$ thick layer of $\mathrm{SiO}_{2}$ by using flow cell ( $Q$-Sense, Biolin Scientific). Between adsorption steps (10 minutes) sensor was rinsed with corresponding salt solution (5 minutes). Flow rate was adjusted to $150 \mu \mathrm{L} \mathrm{min}^{-1}$. QCM-D is a technique which uses acoustic waves obtained by oscillation of piezoelectric material (in this case quartz crystal) to gather the information about the amount of the other material adsorbed on its surface. Adsorption causes dampening of the oscillation, so that the mass adsorbed on the surface is proportional to the frequency change. Frequency and dissipation change of fundamental and few higher harmonics (till $13^{\text {th }}$ ) during formation of polyelectrolyte multilayers were monitored simultaneously and recorded in Qsoft and all the data were processed in Qtools software. Thickness of the layers was calculated according to viscoelastic Voight L1 model and according to Sauerbrey relation:

$$
\Delta m=\frac{C}{n} \Delta f
$$

where $\Delta m$ is the mass adsorbed per surface area, $\Delta f$ frequency change of oscillating quartz crystal caused by adsorption, $n$ is the ordinal number of harmonic used in calculation, and $C$ is the constant which depends on the thickness, density and fundamental frequency of quartz. For $5 \mathrm{MHz}$ crystal the constant $C$ equals $-17.7 \mathrm{ng} \mathrm{cm}^{-2} \mathrm{~Hz}^{-1}$. Sauerbrey equation is used in the case when dissipation change is too small (rigid layers) or no difference between harmonics can be observed, and more generally in the case of thin layers (adsorbed mass is small relative to the mass of quartz crystal). In all other cases, it is justified to use viscoelastic model.[21]

\section{RESULTS AND DISCUSSION}

\section{Zeta-potential Measurements}

Zeta-potential measurements performed in the frame of this study could be divided in two groups. In the first part, the zeta-potential values of silica particles in $\mathrm{NaCl}$ solution

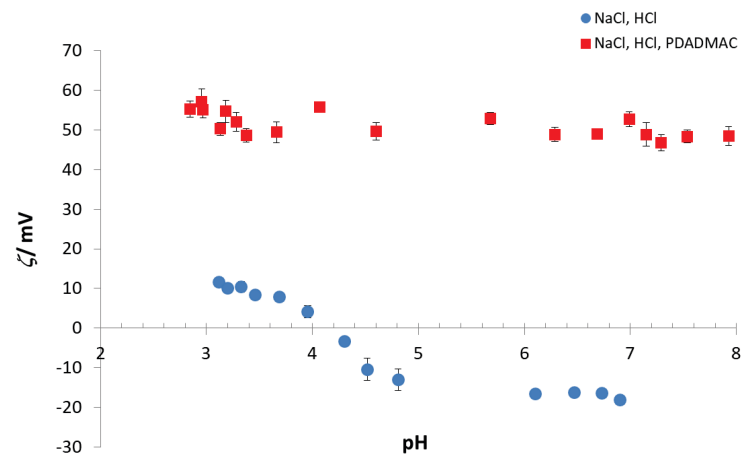

Figure 1. Dependence of the zeta-potential of silica particles $\left(\gamma=1 \mathrm{~g} \mathrm{dm}^{-3}\right)$ with and without adsorbed PDADMAC on $\mathrm{pH}$ of the suspension; ionic strength $\left(I_{c}=0.011 \mathrm{~mol} \mathrm{dm}^{-3}\right)$ was adjusted with $\mathrm{NaCl}, \mathrm{c}_{\mathrm{m}}(\mathrm{PDADMAC})=5 \times 10^{-3} \mathrm{~mol} \mathrm{dm}^{-3}, \theta=25^{\circ} \mathrm{C}$.

with and without adsorbed polyelectrolyte (PDADMAC) were measured as the function of $\mathrm{pH}$. In that way the isoelectric point of silica could be established. Moreover, the $\mathrm{pH}$ range which is appropriate for the polyelectrolyte buildup could be estimated. In Figure 1 the dependence of zetapotential with and without adsorbed PDADMAC on $\mathrm{pH}$ is shown. Silica particles were suspended in $\mathrm{NaCl}$ solution and for $\mathrm{pH}$ adjustment $\mathrm{HCl}$ and $\mathrm{NaOH}$ were used.

From the results presented in Figure 1 it could be concluded that the isoelectric point of silica could be estimated to be at $\mathrm{pH} \approx 4$ which is in accordance with literature values. ${ }^{[22]}$ The presence of PDADMAC at all examined $\mathrm{pH}$ values led to the positively charged particles. On the basis of these conclusions in the described experiments silica particles were prepared at $\mathrm{pH} \approx 6$ in order to enable the adsorption of the positively charged polyelectrolyte in the first PEM layer.

In order to establish if zeta-potential measurements are useful tool in studying the formation of PDADMAC-PSS multilayers on silica particles (as was shown earlier for formation of the same system on polystyrene latex particles $^{[23,24]}$ and, even more importantly, if such experiments are suitable for investigation of the influence of ionic strength and electrolyte type of that process, we adsorbed in alternate manner positively and negatively charged polyelectrolyte. For every adsorbed layer we measured the zeta-potential. For adsorption experiments polyelectrolyte solutions $\left(c(\right.$ PDADMAC $)=c($ PSS $\left.)=5 \times 10^{-3} \mathrm{~mol} \mathrm{dm}^{-3}\right)$ were prepared at $\mathrm{pH} \approx 6$. Since at that $\mathrm{pH}$ silica is negatively charged the first adsorbed polyelectrolyte was positively charged PDADMAC. After the adsorption of the abovementioned polycation, polyanion PSS was adsorbed on silica particle covered with PDADMAC. The change in zeta-potential sign reveals that the oppositely charged polyelectroIyte was successfully adsorbed. The procedure was repeated for two other polyelectrolyte layers. The ionic strength of solution and the electrolyte type were varied and the results will be presented in the following two paragraphs. 


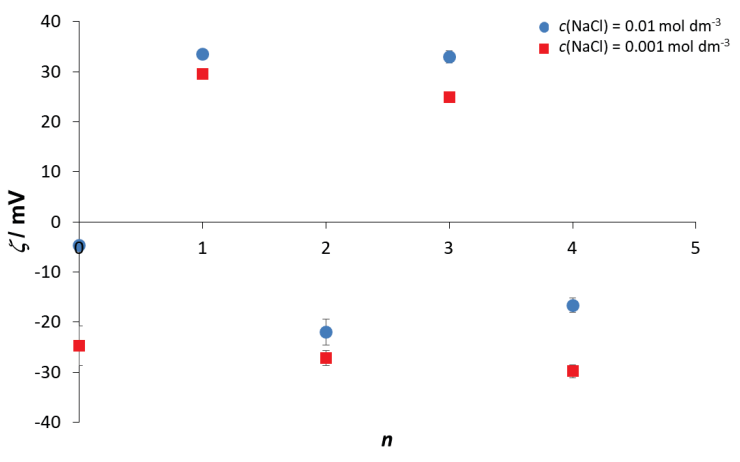

Figure 2. The dependence of zeta-potential on the number of polyelectrolyte layers formed on silica particles $(\gamma=1$ $\mathrm{g} \mathrm{dm}^{-3}$ ) obtained at two different $\mathrm{NaCl}$ concentrations (0.01

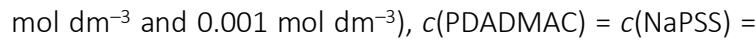
$5 \times 10^{-3} \mathrm{~mol} \mathrm{dm}^{-3}, \theta=25^{\circ} \mathrm{C}$.

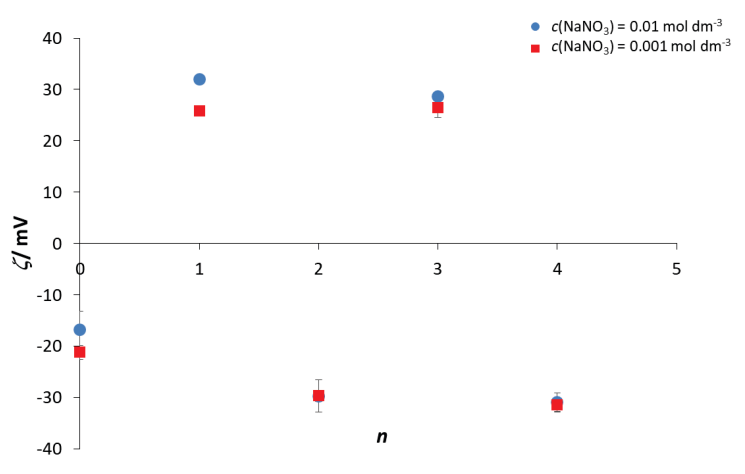

Figure 3. The dependence of zeta-potential on the number of polyelectrolyte layers formed on silica particles $(k=1 \mathrm{~g}$ $\mathrm{dm}^{-3}$ ) obtained at two different $\mathrm{NaNO}_{3}$ concentrations (0.01 $\mathrm{mol} \mathrm{dm} \mathrm{m}^{-3}$ and $\left.0.001 \mathrm{~mol} \mathrm{dm}^{-3}\right), c_{\mathrm{m}}($ PDADMAC $)=c_{\mathrm{m}}(\mathrm{NaPSS})$ $=5 \times 10^{-3} \mathrm{~mol} \mathrm{dm}^{-3}, \theta=25^{\circ} \mathrm{C}$.

\section{IONIC STRENGTH EFFECT}

For studying the influence of electrolyte concentration on the multilayer build-up process all the samples were prepared in sodium chloride and sodium nitrate solutions at the different salt concentrations: $0.01 \mathrm{~mol} \mathrm{dm}^{-3}$ and 0.001 mol dm ${ }^{-3}$.

From the results presented in Figures 2 and 3 it could be concluded that in both cases ( $\mathrm{NaCl}$ and $\mathrm{NaNO}_{3}$ case) the mobility of pure silica particles was, as expected, lower in the case of the higher ionic strength. However, no significant influence of ionic strength on zeta-potential was observed in the case of silica particles covered with polyelectrolytes. That is in accordance with the results obtained in our earlier studies $[25,26]$ about PAH-PSS complexation in solution in the same electrolyte concentration range. Moreover, Delgado and co-workers [27] showed that contrary to the bare magnetite particles, citratecoated particles show the mobility which is practically independent of ionic strength above $10^{-2} \mathrm{~mol} \mathrm{dm}^{-3}$ concentration of $\mathrm{NaNO}_{3}$ which is typical for soft particles.

\section{ELECTROLYTE TYPE EFFECT}

In the second part, we examined the influence of added supporting electrolyte concentration on the formation of polyelectrolyte multilayers. The results obtained in the presence of sodium chloride and sodium nitrate at $I_{c}=0.01$ mol dm ${ }^{-3}$ are compared in Figure 4.

From the results presented in Figure 4 it seems that the effect of the electrolyte type on the zeta-potential of polyelectrolyte multilayers is more pronounced after the adsorption of the negatively charged polyelectrolyte than after the adsorption of the positively charged. However, these effects are rather small and often in the range of the experimental error. The results obtained at lower ionic strength in the presence of the same salts showed that the electrolyte type effect is even less pronounced than at $I_{c}=$ $0.01 \mathrm{~mol} \mathrm{dm}^{-3}$.

It could be concluded here that the zeta-potential measurements could be generally used for examining the build-up of polyelectrolyte multilayers of metal oxide particles. The effect of ionic strength and the influence of the electrolyte type on the PEM formation process were not significantly pronounced in the examined ionic strength range. Therefore, taken into account the limitations of the zeta-potential measurements at high ionic strength, the effects at higher salt concentrations were studied by means of quartz crystal microbalance with dissipation monitoring.

\section{QCM-D Measurements}

The formation and properties of the PEMs build-up using the same polyelectrolyte pair as in the case of the zeta-potential measurements (PDADMAC/PSS pair) at higher salt concentrations were examined using QCM-D measurements. Again, ionic strength and electrolyte type effect were studied.

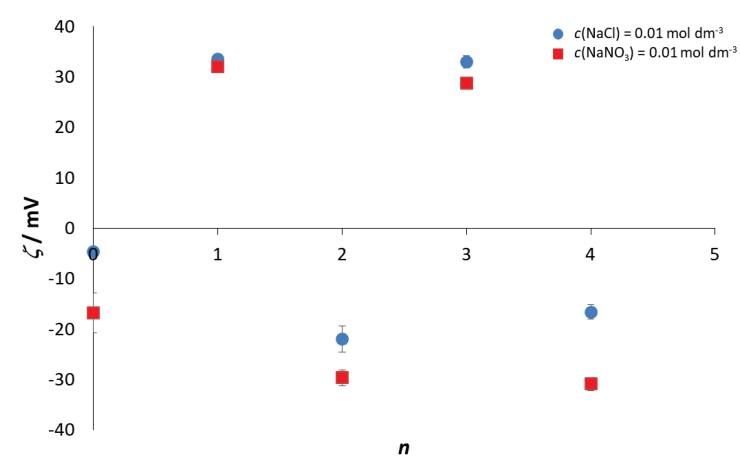

Figure 4. The dependence of zeta-potential on the number of polyelectrolyte layers formed on silica particles $(\gamma=1 \mathrm{~g}$ $\mathrm{dm}^{-3}$ ) obtained in the presence of two different electrolytes $\mathrm{NaNO}_{3}$ and $\mathrm{NaCl} ; I_{c}=0.01 \mathrm{~mol} \mathrm{dm}{ }^{-3}, c_{m}($ PDADMAC) $=$ $c_{\mathrm{m}}($ NaPSS $)=5 \times 10^{-3} \mathrm{~mol} \mathrm{dm}^{-3}, \theta=25^{\circ} \mathrm{C}$. 


\section{IONIC STRENGTH EFFECT}

The increase in the concentration of salt in all three examined cases $\left(\mathrm{NaCl}, \mathrm{NaBr}\right.$ and $\mathrm{NaNO}_{3}$ ) led to the larger frequency shifts during assembly of PDADMAC/PSS, as shown in Figures 5.-7. These frequency shifts are proportional to the mass adsorbed on the surface and thickness of the corresponding layer(s). The higher influence could be observed in the case of nitrate and bromide, than in the case of chloride salt.

\section{ELECTROLYTE TYPE EFFECT}

When the results obtained for various salts (Figures 5.-7.) are compared, it could be concluded that at lower concentration of salt $\left(c=0.1 \mathrm{~mol} \mathrm{dm}^{-3}\right)$ no significant difference between the thickness of the layers formed in solution of three investigated salts was observed (not presented here). At $0.5 \mathrm{~mol} \mathrm{dm}^{-3}$ the difference was more pronounced, suggesting the larger effect in the case of bromide and nitrate than in the case of chloride (Figure 8.). Each of successively deposited layers became thicker, pointing out that overcharging extent is not the same in each layer and that diffusion of polyelectrolyte chains takes place within the whole multilayer (especially here where we talk about small number of deposited layers). Similar behaviour has been already observed elsewhere in $\mathrm{NaCl}$ solution. ${ }^{[10,28]}$ The influence of various counteranions on the properties of PDADMAC-PSS multilayers (but for thin dry PEMs) was studied using ellipsometry and AFM by Salomäki et al [29] who found out that the thickness follows the Hofmeister series reasonably well.

Our results suggest that, in order to obtain a deeper insight into the interpolyelectrolyte neutralisation at surfaces, a more detailed investigation of ion-specific effects on reactions between PDADMAC and PSS in solution would be very valuable, as done earlier for complexation of poly(acrylate) anion with poly(allylammonium) cation [30]. According to our preliminary unpublished results obtained for polyelectrolyte complexation in solution, counteranion effects on assembly of both negative and positive PDADMAC-PSS complexes or on their aggregation could be observed, too. However, that effect was more pronounced in the case of positively charged complexes. On the contrary, results regarding interpolyelectrolyte neutralization between PAH/PSS pair show no significant difference between assemblies of negative complexes in solution of various alkali-metal salts. ${ }^{[25]}$ It is obvious that behaviour of polyelectrolyte complexes depends on the type of polyelectrolyte pair used, i.e. on the strength of their interaction. ${ }^{[31]}$ For that reason, our next step is to find correlation between interpolyelectrolyte neutralization in solution and at the surface and try to answer questions about apparent differences between these two types of nanocomposites.

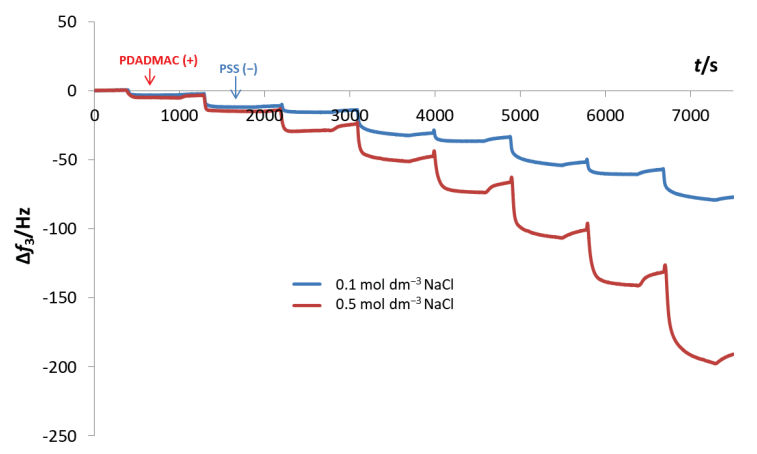

Figure 5. lonic strength effect on the frequency of the $3^{\text {rd }}$ harmonic of oscillating quartz crystal in solution of $\mathrm{NaCl}$ during assembly of PDADMAC/PSS multilayers at $25{ }^{\circ} \mathrm{C}$. $c_{m}($ PDADMAC $)=c_{m}(P S S)=1 \times 10^{-3} \mathrm{~mol} \mathrm{dm}^{-3}$, flow rate $=150$ $\mu \mathrm{L} \min ^{-1}$

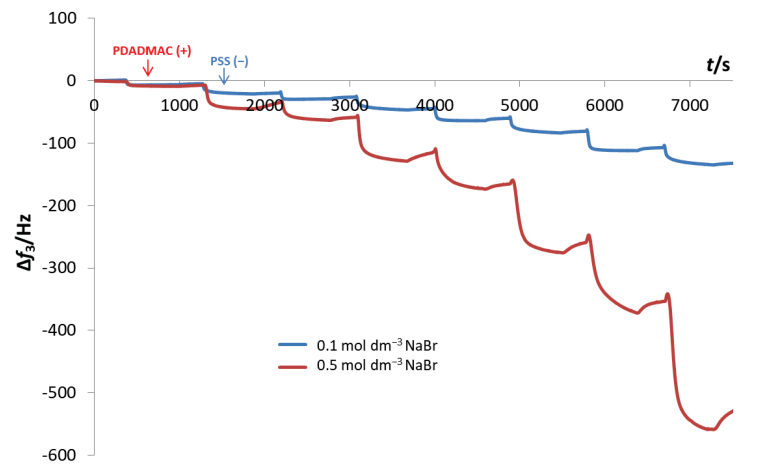

Figure 6. lonic strength effect on the frequency of the $3^{\text {rd }}$ harmonic of oscillating quartz crystal in solution of $\mathrm{NaBr}$ during assembly of PDADMAC/PSS multilayers at $25{ }^{\circ} \mathrm{C}$. $c_{m}($ PDADMAC $)=c_{m}($ PSS $)=1 \times 10^{-3} \mathrm{~mol} \mathrm{dm}^{-3}$, flow rate $=150$ $\mu \mathrm{L} \min ^{-1}$.

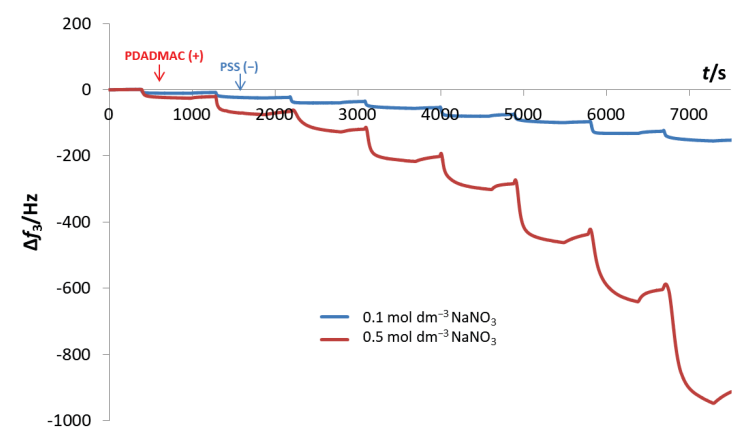

Figure 7. Ionic strength effect on the frequency of the $3^{\text {rd }}$ harmonic of oscillating quartz crystal in solution of $\mathrm{NaNO}_{3}$ during assembly of PDADMAC/PSS multilayers at $25^{\circ} \mathrm{C}$. $c_{m}($ PDADMAC $)=c_{m}($ PSS $)=1 \times 10^{-3} \mathrm{~mol} \mathrm{dm}^{-3}$, flow rate $=150$ $\mu \mathrm{L} \min ^{-1}$. 


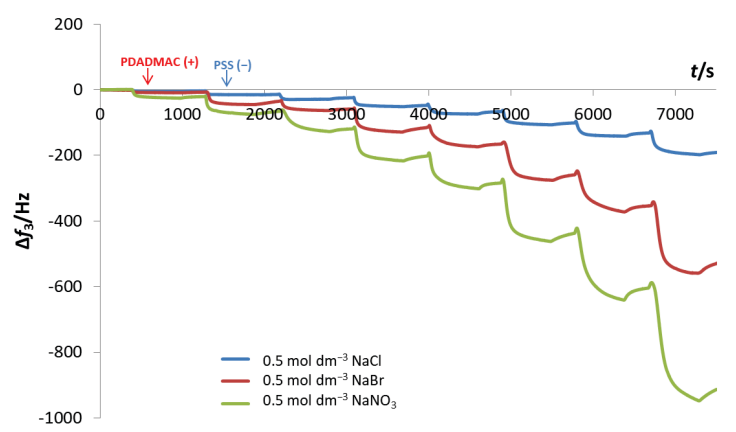

Figure 8. Electrolyte type effect on the frequency of the $3^{\text {rd }}$ harmonic of oscillating quartz crystal in solution of

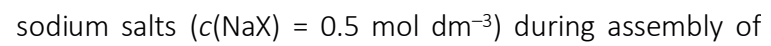
PDADMAC/PSS multilayers at $25^{\circ} \mathrm{C} . c_{m}($ PDADMAC $)=c_{m}(P S S)$ $=1 \times 10^{-3} \mathrm{~mol} \mathrm{dm}^{-3}$, flow rate $=150 \mu \mathrm{L} \mathrm{min}^{-1}$.

QCM-D measurements presented in Figures 5.-8. were always repeated twice. The experimental error of the measured frequency change was estimated to be $\pm 5 \%$ in case of $\mathrm{NaCl}$, and $\pm 10 \%$ in case of $\mathrm{NaBr}$ and $\mathrm{NaNO}_{3}$. For the simplicity of Figures (many experimental data points), error bars are omitted.

\section{GROWTH OF POLYELECTROLYTE MULTILAYERS}

Linear growth of PDADMAC/PSS multilayer in presence of $\mathrm{NaCl}$, and change from linear to exponential growth in presence of $\mathrm{NaBr}$ and $\mathrm{NaNO}_{3}$ could be observed, even for quite small number of deposited layers (Figure 9).

For higher number of deposited layers, we should expect the exponential growth to be even more pronounced in the case of bromide and nitrate. This leads to conclusion that choice of salt type and its concentration in solution enables manipulation of multilayer (and also of complex) structure and properties (viscoelastic properties, thickness, water content etc.).

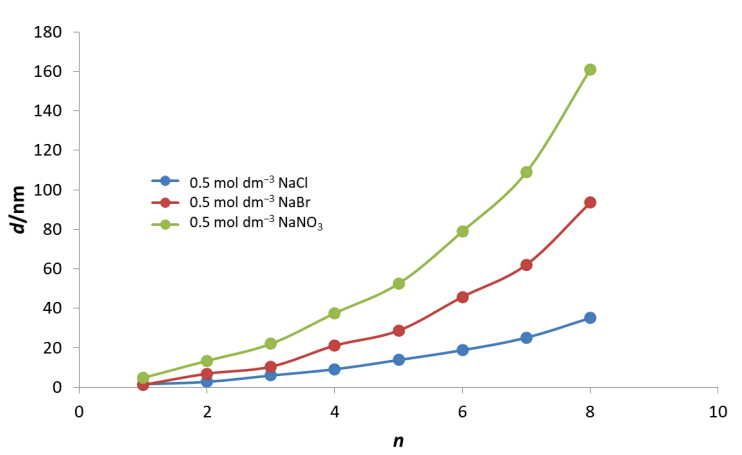

Figure 9. Dependence of thickness of PDADMAC/PSS multilayer on the number of the adsorbed layer in solution of sodium salts $\left(c(\mathrm{NaX})=0.5 \mathrm{~mol} \mathrm{dm}^{-3}\right)$ at $25^{\circ} \mathrm{C}$, $c_{m}($ PDADMAC $)=c_{m}($ PSS $)=1 \times 10^{-3} \mathrm{~mol} \mathrm{dm}^{-3}$, flow rate $=150$ $\mu \mathrm{L} \mathrm{min}^{-1} . d$ was calculated according to Voight (viscoelastic) model in QTools.

\section{CONCLUSIONS}

The herein described results about the influence of ionic strength and sodium salt type on PDADMAC-PSS multilayers on silica surfaces allow us to confirm that the abovementioned effects are substantial in the process of PEM formation. Both electrophoretic light scattering and quartz crystal microbalance with dissipation monitoring techniques proved to be useful methods for investigating the formation of polyelectrolyte multilayers in the presence of various salts. It was shown that the process of PDADMAC/PSS multilayer is very sensitive to various experimental conditions. At the highest studied ionic strength $\left(I_{c}\right.$ $=0.5 \mathrm{~mol} \mathrm{dm}^{-3}$ ) the most pronounced results were obtained showing larger multilayer thickness in the case of bromide and nitrate than in the case of chloride ions. It could be concluded that the obtained results are valuable since they provide additional evidence that the formation of polyelectrolyte multilayers can be controlled by variation of the salt type and ionic strength and therefore these processes could be tuned offering a wide range of possibilities for their future application.

Acknowledgment. The research was financially supported by Croatian Science Foundation under the project SAQUINT (IP2014-09-6972). The authors thank Tomislav Vuletić (Institute of Physics, Zagreb) for providing QCM-D setup for measurements.

\section{REFERENCES}

[1] G. Decher, J. D. Hong, Macromol. Chem. Macromol. Symp. 1991, 46, 321.

[2] P. Schwinte, J. C. Voegel, C. Picart, Y. Haikel, P. Schaaf, B. Szalontai, J. Phys. Chem. B 2001, 105, 11906.

[3] K. Sato, J. Anzai, Molecules 2013, 18, 8440.

[4] J. T. Zhang, L. S. Chua, D. M. Lynn, Langmuir 2004, 20, 8015.

[5] R. v. Klitzing, Phys. Chem. Chem. Phys. 2006, 8, 5012.

[6] M. Schönhoff, Curr. Opinion Colloid Interface Sci. 2003, 8, 86.

[7] P. Schwinte, J. C. Voegel, C. Picart, Y. Haikel, P. Schaaf, B. Szalontai, J. Phys. Chem. B 2001, 105, 11906.

[8] D. Kovačević, S. van der Burgh, A. de Keizer, M. A. Cohen Stuart, Langmuir 2002, 18, 5607.

[9] D. Kovačević, S. van der Burgh, A. de Keizer, M. A. Cohen Stuart, J. Phys. Chem. B 2003, 107, 7998.

[10] K. Tang, N. A. M. Besseling, Soft Matter 2016, 12, 1032.

[11] A. Vidyasagar, C. Sung, R. Gamble, J. L. Lutkenhaus, ACS Nano 2012, 6, 6174. 
[12] C. Picart, Ph. Lavalle, P. Hubert, F. J. G. Cuisinier, G. Decher, P. Schaaf, J. C. Voegel, Langmuir 2001, 17, 7414.

[13] A. Ge, M. Matsusaki, L. Qiao, M. Akashi, S. Ye, Langmuir 2016, 32, 3803.

[14] M. Müller, B. Kessler, W. Ouyang, Z. Phys. Chem. 2007, 221, 127.

[15] C. Gergely, S. Bahi, B. Szalontai, H. Flores, P. Schaaf, J. C. Voegel, F. J. G. Cuisinier, Langmuir 2004, 20, 5575.

[16] P. Schwinte, V. Ball, B. Szalontai, Y. Haikel, J. C. Voegel, P. Schaaf, Biomacromolecules 2002, 3, 1135.

[17] X. Zan, Z. Su, Thin Solid Films 2010, 518, 5478.

[18] S. Y. Wong, L. Han, K. Timachova, J. Veselinovic, M. N. Hyder, C. Ortiz, A. M. Klibanov, P. T. Hammond, Biomacromolecules 2012, 13, 719.

[19] D. Kovačević, R. Pratnekar, K. Godič Torkar, J. Salopek, G. Dražić, A. Abram, K. Bohinc, Polymers 2016, 8, 345:1 - 345:12.

[20] D. Bütergerds, C. Kateloe, C. Cramer, M. Schönhoff, J. Polym. Sci., Part B: Polym. Phys. 2017, 55, 425.
[21] M. Dixon, J Biomol Tech 2008, 19, 151.

[22] M. Kosmulski, J. Colloid Interface Sci. 2009, 337, 439.

[23] G. B. Sukhorukov, E. Donath, H. Lichtenfeld, E. Knippel, M. Knippel, A. Budde, H. Möhwald, Colloids Surf. A: Physicochem. Eng. Asp 1998, 137, 253.

[24] F. Caruso, H. Lichtenfeld, E. Donath, H. Möhwald, Macromolecules 1999, 32, 2317.

[25] J. Požar, D. Kovačević, Soft Matter 2014, 10, 6530.

[26] J. Požar, J. Salopek, M. Poldrugač, D. Kovačević, Colloids Surf., A 2016, 510, 159.

[27] J. L. Viota, K. Rudzka, A. Trueba, I. Torres-Aleman, A. V. Delgado, Langmuir 2011, 27, 6426.

[28] R. A. Ghostine, M. Z. Markarian, J. B. Schlenoff, J. Am. Chem. Soc. 2013, 135, 7636.

[29] M. Salomäki, P. Tervasmäki, S. Areva, J. Kankare, Langmuir 2004, 20, 3679.

[30] T. Kremer, D. Kovačević, J. Salopek, J. Požar, Macromolecules, 2016, 49, 8672.

[31] J. Fu, H. M. Fares, J. B. Schlenoff, Macromolecules 2017, 50, 1066. 